See discussions, stats, and author profiles for this publication at: https://www.researchgate.net/publication/265390328

\title{
A congruence approach to the study of bilingual compound verbs in Northern Belize contact Spanish
}

Article in Spanish in Context · January 2014

Dol: 10.1075/sic.11.2.05bal

\section{CITATIONS}

13

3 authors:

Osmer Balam

College of Wooster

13 PUBLICATIONS 95 CITATIONS

SEE PROFILE

Damaris Mayans

Colby College

8 PUBLICATIONS 14 CITATIONS

SEE PROFILE

Some of the authors of this publication are also working on these related projects:

L3 Acquisition View project

162

Ana De Prada Pérez

National University of Ireland, Maynooth

16 PUBLICATIONS 62 CITATIONS

SEE PROFILE 


\title{
A congruence approach to the study of bilingual compound verbs in Northern Belize contact Spanish
}

\author{
Osmer Balam, Ana de Prada Pérez and Dámaris Mayans
}

\begin{abstract}
Attested in a wide variety of contact situations, bilingual compound verbs (BCVs) have baffled linguists, as they are innovative hybrid constructions that appear superfluous. In the current study, we examine BCVs in Northern Belize, where Spanish/English language alternation occurs alongside the pervasive use of Belizean Kriol, Belize's lingua franca. We analyze Northern Belize code-switchers' acceptability judgments and use of BCVs in oral production to determine whether stativity and/or verb frequency constrain the incorporation of BCVs as previously contended. The quantitative analysis of acceptability judgments and 553 canonical BCVs from 25 adolescent and 18 post-adolescent speakers revealed that BCVs are not constrained by stativity or verb frequency. We contend that although there are syntactic constraints, bilinguals'/multilinguals' use of their linguistic resources is largely dependent on social factors (Sebba 1998). In the case of Northern Belize, where speakers do not perceive code-switching as illegitimate but rather embrace it and associate it with their mixed, multiplex identity, positive attitudes to non-standard varieties may have paved the way for the ubiquitous use of BCVs. The availability of a native Spanish/Mayan BCV model may have also catalyzed the process. BCVs in Northern Belize merit further investigation as they are innovative structures with Creoloid features that reflect code-switchers' creative ability to capitalize on structural parsimony.
\end{abstract}

Keywords: bilingual compound verbs, Northern Belize code-switching, adaptive simplification

\section{Introduction}

A substantial body of variationist and generative work has investigated the principles and restrictions that underlie bilingual speech in typologically diverse contact 


\section{Osmer Balam, Ana de Prada Pérez and Dámaris Mayans}

situations. This research has yielded influential models and constraints that have fundamentally contributed to our current understanding of "classic code-switching" (Myers-Scotton 1998) and bilingualism in 'stable' linguistic contexts, where the assumption is that bilinguals position themselves, in Grosjean's (1998) terms, along a language continuum where they activate one or two languages. Implicitly understood in this line of work, particularly on the syntax of code-switching (CS), is that language alternation is possible only when there is cross-linguistic congruence or 'equivalence' between the two discrete, monolingual grammars (for further discussion, see Sebba 2009, 41). However, since few attempts have examined how the notion of categorial equivalence applies to multilingual contact situations where discrete codes are not the linguistic norm, our understanding of "composite" CS (Myers-Scotton 1998) and the intricately intertwined historical and sociocultural factors that undergird these types of contexts remain limited.

The current study examines BCVs in Northern Belize (NB), an understudied Spanish contact situation, which has previously been noted for its younger speakers' pervasive use of code-mixing (Balam 2013a; Balam 2013b). Consonant with recent work on CS, which underscores the necessity for a more integrative approach to the study of bilingual speech phenomena (MacSwan and McAlister 2010; Rodriguez-González and Parafita-Couto 2012), the current study examines speakers' acceptability judgments and use of BCVs in spontaneous oral production in order to provide a more thorough analysis of the use of BCVs in NB.

Whereas extensive research has been carried out on BCVs in Indic languages and/or Indic contact situations (Chatterjee 2012; Muysken 2000; Ritchie and Bhatia 1996, Romaine 1986; Sankoff, Poplack and Vanniarajan 1990, among many others), less research has been carried out vis-à-vis BCVs in Spanish contact situations. Particularly in the case of Belize, where BCVs have been described as "an Anglicized feature of particular interest because of its frequency" (Hagerty 1996, 136), scant research has been carried out to document and understand the use of BCVs, especially in relation to the region's historical and sociolinguistic milieu. The present study contributes to the study of BCVs by investigating whether stativity and/or verb frequency constrain the incorporation of BCVs as previously contended (Fuller Medina 2005; Jenkins 2003; Reyes 1982).

\section{Language contact in Northern Belize}

Bolle $(2000,220)$ aptly describes Belize as un verdadero caleidescopo de lenguas y culturas 'a true kaleidoscope of languages and cultures.' Given the status of English as the official language of Belize, Bolle further adds that Belize constitutes a linguistic frontier with the Spanish-speaking world. Although Belize is a contemporary 
test case of Spanish in contact with English and Belizean Kriol (BK), scant research has been carried out on this contact situation. Most of the linguistic research that has been carried out on Belize focuses on the Creole contact situation (Escure 1982; Hellinger 1973; Le Page 1984; Le Page and Tabouret-Keller 1985; Migge 1995; Young 1973, among others). The case of Spanish, however, has received limited attention, albeit the fact that from the 1990's, Spanish has become the language spoken by the majority in Belize (Bolle 2001; Moberg 1997; Shoman 2010).

Spanish in Belize traces its history back to the 1840's when Mexican Mestizo and Mayan refugees, escaping the Caste War in Yucatan, settled in the Northern districts of Corozal and Orange Walk. Contrary to the early twentieth century, Spanish/Mayan bilingualism in NB is very limited today, and as Brockmann (1979) predicted, the current trend in Orange Walk is a shift towards Spanish/English (or BK) bilingualism and/or Spanish/English/BK trilingualism. Given the 'diffuse' Spanish/English/Creole contact situation in Belize (Le Page and Tabouret-Keller 1985), where wide variation exists between the different codes spoken by Hispanic Belizeans, in the current paper, we adopt Gardner-Chloros' $(1995,86)$ conception of CS: a chameleon-like phenomenon, which encompasses a variety of concomitant interlingual phenomena, and which in essence makes it "[in]separable either ideologically or in practice, from borrowing, interference or pidginization."

\section{Bilingual compound verbs}

The canonical BCV in Spanish/English CS consists of a fully inflected LV hacer 'do/make' from the recipient language, which co-occurs with an infinitive verb from the source language (González-Vilbazo and López 2011; Muysken 2000). As (1) exemplifies, the LV provides information on number, grammatical person, and TAM features, whereas the English verb contributes the semantic content.

(1) Hicieron rent un golf cart

Do.3RDPL rent.INF a golf cart

"They rented a golf cart"

(Speaker AD18, 16 years old)

BCVs have been attested in many CS varieties including different language pairings (for further discussion, see Muysken 2000 and Edwards and Gardner-Chloros 2007). However, in the case of Spanish/English CS, BCVs have only been attested in some communities in Southwest U.S. (Jenkins 2003; Reyes 1982; Wilson Vergara 2013) and Belize (Fuller Medina 2005; Hagerty 1996). It is, however, unattested in the speech of Puerto Rican, Dominican and Cuban bilinguals (Jenkins 2003). In the literature on varieties of U.S. Spanish, English verbs are typically morphophonologically incorporated into Spanish (e.g. Field 2002; Smead 1998) 
through derivational blends such as taipear 'to type' and huachar 'to watch, look, see' (Reyes 1982, 159), whereas the incorporation of BCVs is rare and typically met with rejection by Spanish/English bilinguals in the U.S. (Reyes 1982; Toribio et al. 2012).

Thus far, the extant work on BCVs in Spanish contact situations has largely focused on the restrictions that constrain the incorporation of BCVs in bilingual speech, whereas less attention has been given to sociolinguistic and/or historical factors that may help to account for the use of BCVs. For example, in their Minimalist analysis of BCVs from Spanish/German CS data, González-Vilbazo and López argue that the LV hacer is incompatible with passives. They explain that when a German verbal root cannot value or satisfy Spanish little v's conjugation class feature, the LV hacer must be inserted to save the derivation. In BCVs, the LV hacer spells out as little $v$, and the lexical verb does not incorporate into little $v$. In the case of passives, they argue that the lexical verb remains unincorporated; as a consequence, the internal argument cannot raise to subject position. As a result, BCVs are incompatible with passives.

Factors that constrain the incorporation of BCVs have also been investigated by variationist researchers. For example, Reyes (1982) argued that the hacer + V' syntactic frame was only employed with low frequency Spanish verbs. Jenkins (2003), who based his analysis on interview data from 15 native bilinguals from northern New Mexico and southern Colorado, concurs that this construction occurs with low-frequency verbs or "new" verbs. Following Reyes, Jenkins (2003, 198) claimed that "there is no functional need for a bilingual to shift to English for a frequently used verb".

Some of these hypotheses were tested by Fuller Medina (2005), who collected data in Belize. Fuller Medina investigated whether BCVs were constrained by verb frequency and stativity. Data were collected via a picture description task from 21 Spanish/English bilinguals from different parts of Belize. Fuller Medina's results showed that $90 \%$ of tokens belonged to the class of dynamic verbs, while only $10 \%$ were stative verbs. Consequently, she interpreted this as evidence that BCVs are restricted by stativity. There was much stronger evidence for the restriction based on verb frequency, as participants markedly produced the periphrastic construction with low frequency verbs rather than high frequency verbs such as eat, drink, get up, etc.

Proposed as a potential universal property of CS (Edwards and GardnerChloros 2007; González-Vilbazo and López 2012), BCVs continue to intrigue linguists as they remain problematic for current CS constraints and models such as 
the Matrix Language Frame Model (Myers-Scotton 2002). ${ }^{1}$ While some researchers analyze 'hacer $+V$ ' as an instance of lexical borrowing (Fuller Medina 2005; Jenkins 2003; Reyes 1982; Wohlgemuth 2009), others examine it as an innovative form of CS (González-Vilbazo and Lopéz 2011; Muysken 2000; Ritchie and Bhatia 1996; Sebba 1998) with features of creolization (Gardner-Chloros 1995, 2010). Note that BCVs have been attested in Hindi/English Creole bilingual speech in Trinidad and Guyana (c.f. Muysken, 2000, 209). More recently, Wilson Vergara $(2013,132)$ contends that 'hacer $+V$ ' is neither a borrowing nor a code-switch but a grammaticalized hybrid structure that may belong to a "new grammar" which develops as a result of bilingual discourse practices. Thus, linguists still do not concur on what exactly 'hacer $+\mathrm{V}$ ' is and what triggers its emergence. Furthermore, the questions of when and why these bilingual verbs are incorporated in bilingual/ multilingual discourse still remain largely unanswered.

Although Fuller Medina (2005) undoubtedly provided valuable insights into the use of BCVs in Belize, her analysis was limited in that judgment data were not reported on. Additionally, she did not control for dialectal differences between bilingual speakers who live in the Western part of Belize, who clearly speak a Spanish variety considerably different from the variety in NB (Hagerty 1979). Also noteworthy is that her participants were speakers of different ages. In previous work on Spanish/English communities in the U.S., older adults have been noted for their preferential use of monolingual Spanish, whereas CS has been specifically associated with the younger generation (e.g. Elías-Olivares 1976; Ornstein-Galicia 1987). It may partially be that as a result of these oversights, her corpus of nine hours of recorded speech yielded only $35 \mathrm{BCVs}$, which does not reflect the high frequency of BCVs Hagerty (1996) observed. In view of these facts, the present study sought to examine the effect that stativity and verb frequency have on the acceptability and oral production of BCVs among adolescent and post-adolescent code-switchers from Orange Walk, Northern Belize.

\section{The present study}

In the current study, we particularly examined whether stativity and verb frequency are constraining factors in the use of BCVs. Regarding verb frequency, for

1. González-Vilbazo and López (2011), for example, point out that the Matrix Language Frame Model cannot account for BCVs, as it fails to account for the word order which is determined by the light verb, and not by the matrix language. In their analysis, they argue that in feature spreading, it is the head of a phase (i.e. hacer) that determines the grammatical properties of the whole phase. 
instance, it is possible that in oral production, the 'need' to switch languages with infrequent verbs is a deterministic factor. In a judgment task, on the other hand, verb frequency might not be of importance as there is nothing in the syntax to ban the switch into a frequent verb. In order to address these questions, we collected acceptability judgments and oral production data in Orange Walk, Belize.

A total of 25 adolescent participants (ages 14-17), of which 15 were males and 10 were female, were recruited from two different high schools in Orange Walk, Belize. Additionally, 13 post-adolescent participants (ages 19-26), of which 8 were males and 5 were females, were recruited via purposeful sampling, from the Orange Walk community at large. All participants were Orange Walk-born natives and had either completed or were currently obtaining their secondary education in Orange Walk. They were all speakers of Northern Belizean Spanish (NBS), English and BK, who reported using NBS more frequently (Mean: 7.2) than BK (Mean: 7.1), CS (Mean: 6.3) or English (Mean: 6.1), on a scale where 1 indicated 'Never' and 8 indicated 'Everyday, most of the time during the day.'

Participants completed two tasks. The first task was an Acceptability Judgment Task (AJT), which elicited speakers' well-formedness judgments regarding codeswitched utterances containing BCVs. The task included 54 items, which consisted of 29 test items and 25 fillers. All test items consisted of sentences where participants rated randomized verbal phrases on a 1-4 Likert scale ( $1=$ totally unacceptable, $4=$ totally acceptable). As Figure 1 exemplifies, there were two types of BCVs: canonical and non-canonical (i.e. control structures.) For canonical BCVs, as in (2a), the dependent variable was the form of the verb: an English verb, or a Spanish verb (where the switch is postverbal) or BCV, which was represented at least twice, with different switching patterns in the object. Although the effect of the switching patterns in the object was included in the design, it is not discussed here. We focus our comparison between the BCV sentence that receives the higher rating, switching into an English verb, or switching after the Spanish verb. Therefore, for (2a) we compare sentences (i), (iii), and (iv), since (i), with a mixed DP, was rated higher than (ii). In the case of non-canonical BCVs, as in (2b), the levels of the dependent variable were: no BCV (Spanish control verb with an English main verb), BCV in the control verb, BCV in the main verb or double BCV (control and main verbs).

Sentences were manipulated for predicate type (transitive, unaccusative, control), stativity, and verb frequency. The design, thus, included the following conditions: BCVs with (i) transitive verbs, manipulated for frequency, (ii) stative accusative verbs, manipulated for frequency, (iii) stative unaccusative verbs and (iv) control structures. BCVs with (i) through (iii) were all canonical constructions which have been mentioned in the literature (cf. González-Vilbazo and López 2011), whereas condition (iv) was the only non-canonical BCV explored in the current study. Regarding verb frequency, we followed Fuller Medina's (2005) 
(2a) Danny siempre de su novia en su wallet.
i. hace carry el small photograph
ii. hace carry la fotografía pequeña
iii. carried el small photograph
iv. lleva la small photograph

$\begin{array}{lllll}1 & 2 & 3 & 4 & \text { I don't know } \\ 1 & 2 & 3 & 4 & \text { I don't know } \\ 1 & 2 & 3 & 4 & \text { I don't know } \\ 1 & 2 & 3 & 4 & \text { I don't know }\end{array}$

'Danny always carries his girlfriend's picture in his wallet.'

(2b) Jaime dice que él no
i. espera to win el essay competition
$\begin{array}{lllll}1 & 2 & 3 & 4 & \text { I don't know }\end{array}$
ii. hace expect to win el essay competition
$\begin{array}{lllll}1 & 2 & 3 & 4 & \text { I don't know }\end{array}$
iii. espera hacer win el essay competition $\quad \begin{array}{llllll}1 & 2 & 3 & 4 & \text { I don't know }\end{array}$
iv. hace expect hacer win el essay competition $\begin{array}{llllll}1 & 2 & 3 & 4 & \text { I don't know }\end{array}$

'James says that he doesn't expect to win the essay competition.'

Figure 1. Sample items from the AJT

methodology and operationalized frequency according to word searches (for all conjugated forms of the verb) in the "Corpus Contemporáneo del Español" (Davies 2002). Verbs were classified as low frequency verbs if they had less than 2000 occurrences in the 20th century data, whereas verbs with more than 2000 occurrences in the on-line database were considered high frequency. All sentences were controlled for length and plausibility. All items were written by the first author, a native code-switcher of NB.

Participants additionally engaged in 10-20 minute, semi-structured codeswitched interviews carried out by the first author. In order to collect speech samples that were as closely as possible reflective of the community linguistic norms, interviews were administered in pairs or small groups of peers in order to ensure the production of authentic speech behaviors (Blom and Gumperz 1972). Data from five sociolinguistic interviews with five more post-adolescent speakers were subsequently included to further substantiate the findings of the study. In contrast to previous studies, which have been limited by a relatively small number of tokens (e.g. Fuller Medina 2005, 35 tokens; Romaine 1989, 77 tokens; Toribio et al. 2012, 12 tokens; Wilson Vergara 2013, 62 tokens), the present quantitative analysis is based on 553 canonical BCVs extracted from the interviews.

In an effort to provide a more detailed breakdown of the types of lexical verbs in BCVs, verbs were coded according to categories/verb classes used in other variationist studies (e.g. Aaron 2010) rather than the stative/dynamic distinction used by Fuller Medina (2005). Thus, stativity is subsumed under verb type. For the analysis of stativity, all 553 occurrences were examined independently, as every BCV essentially occurs in possible variation with an English, Belizean Kriol and/or Spanish verb; thus, every BCV represents an instance where the speaker uses the 
bilingual structure over the English, Spanish or Kriol verb or near-equivalent verbal form. However, for the analysis of frequency, following Fuller Medina (2005) and Wilson Vergara (2013), only the 299 different verb types (not the overall 553 occurrences) were considered as the number of times that a verb was repeated has no bearing on the frequency of a specific verb. Verbs with multi-word equivalents (e.g. procrastinate, start over, volunteer) and verbs with Spanish reflexive equivalents (e.g. fit in, get used to) were excluded from the frequency analysis as they constitute a class of verbs whose Spanish equivalents and/or near-equivalents differ both morphologically and semantically. Results from AJT and the oral production data are provided in the following section.

\section{Results}

\subsection{Speakers' intuitions: stativity and frequency in BCVs}

Participants' ratings of BCVs in stative vs non-stative transitives (both frequent and non-frequent) are summarized in Table 1. It is important to note that all participant groups' ratings fall within the acceptance rate. Therefore, all groups accepted BCVs with both stative and non-stative transitives. At the same time, BCVs were also accepted with frequent and infrequent transitives. Interestingly, whereas previous work reported a stativity and a frequency effect, we did not anticipate any effects as there should be no syntactic restriction on the stativity or frequency of the verb in order to switch with a BCV.

In order to examine stativity we compared transitive predicates that were stative vs transitive predicates that were non-stative. We included frequent and infrequent transitive predicates. For frequent transitive predicates, a 2 (stativity: stative vs non-stative) by 4 (speaker group: adolescent females, adolescent males, post-adolescent females, post-adolescent males) repeated measures ANOVA indicated no main effect for stativity, a main effect for speaker group, and no interaction. Male post-adolescent participants rated sentences significantly lower (M: 2.8, SD: .128) than high-school males (M: 3.5, SD: .176). For non-frequent transitive predicates, the same analysis was performed indicating no main effect for stativity, speaker group or stativity by speaker group interaction.

Therefore, our prediction that stativity would not be significant in the AJT bears out in our data. While in oral production speakers may be more sensitive to stativity in their CS, it is not due to the syntax of BCVs as the LV 'hacer' selects for a $\mathrm{V}$ of any type. It could be a general trait of CS and, thus, we would expect to find this stativity effect in CS dialects where instead of BCVs they use an English verb, an issue we leave for further research. 
Table 1. Descriptive statistics for stativity and frequency in BCVs with transitive predicates

\begin{tabular}{lllllr}
\hline $\begin{array}{l}\text { Descriptive statistics: } \\
\text { Stativity in BCVs }\end{array}$ & Stativity & Speaker group & Mean & \multicolumn{1}{l}{$\begin{array}{l}\text { Std. } \\
\text { Deviation }\end{array}$} \\
\hline Non-Frequent transitives & Non-Stative & Adolescent females & 3.55 & 0.33 & 5 \\
& & Adolescent males & 3.41 & 0.53 & 8 \\
& & Post-adolescent females & 3.00 & 0.79 & 10 \\
& & Post-adolescent males & 3.13 & 0.72 & 15 \\
& Total & 3.21 & 0.67 & 38 \\
& & Adolescent females & 3.40 & 0.29 & 5 \\
& & Adolescent males & 3.44 & 0.42 & 8 \\
& & Post-adolescent females & 2.88 & 0.66 & 10 \\
& & Post-adolescent males & 3.02 & 0.45 & 15 \\
& & Total & 3.12 & 0.53 & 38 \\
\hline \multirow{2}{*}{ Non-Stative } & Adolescent females & 3.15 & 0.65 & 5 \\
& & Adolescent males & 3.47 & 0.56 & 8 \\
& & Post-adolescent females & 2.88 & 0.69 & 10 \\
& & Post-adolescent males & 2.78 & 0.44 & 15 \\
& & Total & 3.00 & 0.61 & 38 \\
& & Adolescent females & 3.50 & 0.47 & 5 \\
& \multirow{2}{*}{ Stative } & Adolescent males & 2.56 & 0.35 & 8 \\
& & Post-adolescent females & 2.93 & 0.68 & 10 \\
& & Post-adolescent males & 2.82 & 0.53 & 15 \\
& & Total & 3.09 & 0.61 & 38 \\
\hline & & & &
\end{tabular}

As was the case with stativity, even though an effect has been reported in spontaneous oral production data, we predicted the syntax would not restrict BCVs due to frequency. Therefore, we anticipated all groups would exhibit no frequency effect. To test this hypothesis we compared frequent and infrequent transitive predicates (both stative and non-stative).

The descriptive statistics indicated that overall all speaker groups accepted BCVs with both frequent and non-frequent transitives. We conducted two separate 2 (frequency: high vs low frequency verbs) by 4 (speaker group) repeatedmeasures ANOVAs; one for stative and one for non-stative transitives. Regarding

Table 2. Stativity in BCVs

\begin{tabular}{llll}
\hline $\begin{array}{l}\text { ANOVA results: } \\
\text { Stativity }\end{array}$ & Main effect for stativity & $\begin{array}{l}\text { Main effect for speaker } \\
\text { group }\end{array}$ & $\begin{array}{l}\text { Stativity by speaker } \\
\text { group interaction }\end{array}$ \\
\hline Frequent transitives & $F(1,34)=2.471$, & $F(3,34)=4.421$, & $F(3,34)=.586$, \\
& $p=.13$, & $p=.01$, & $p=.63$, \\
partial $\eta 2=.068$ & partial $\eta 2=.281$ & partial $\eta 2=.049$ \\
Non-frequent & $F(1,34)=1.175$, & $F(3,34)=1.882$, & $F(3,34)=.235$, \\
transitives & $p=.286$, & $p=.151$, & $p=.87$, \\
& partial $\eta 2=.033$ & partial $\eta 2=0.142$ & partial $\eta 2=.020$ \\
\hline
\end{tabular}


stative transitives, the analysis revealed no main effect for frequency (the effect size, however, was small), a main effect for speaker group and no frequency by speaker group interaction. Adolescent males rated BCVs with stative transitives significantly higher than post-adolescent males. With respect to non-stative transitives, no main effect for frequency, speaker group or frequency by speaker group interaction was found.

Table 3. Frequency in BCVs

\begin{tabular}{llll}
\hline $\begin{array}{l}\text { ANOVA results: } \\
\text { Frequency }\end{array}$ & $\begin{array}{l}\text { Main effect for } \\
\text { frequency }\end{array}$ & $\begin{array}{l}\text { Main effect for speaker } \\
\text { group }\end{array}$ & $\begin{array}{l}\text { Frequency by speaker } \\
\text { group interaction }\end{array}$ \\
\hline Stative transitives & $F(1,34)=.059$, & $F(3,34)=4.295$, & $F(3,34)=1.334$, \\
& $p=.81$, & $p=.01$, & $p=.28$, \\
& partial $\eta 2=.002$ & partial $\eta 2=.275$ & partial $\eta 2=.105$ \\
Non-stative transitives & $F(1,34)=3.712$, & $F(3,34)=2.012$, & $F(3,34)=1.051$, \\
& $p=.06$, & $p=.13$, & $p=.38$, \\
& partial $\eta 2=.098$ & partial $\eta 2=0.151$ & partial $\eta 2=.085$ \\
\hline
\end{tabular}

In summary, stativity and frequency were not significant variables in the acceptance of BCVs among Northern Belizean adolescent and post-adolescent males and females. All BCVs were accepted to the same rate with transitive predicates. We did find, however, that male adolescent speakers accepted sentences more than their post-adolescent counterparts, specifically in the stative vs non-stative contrast with frequent transitives and in the frequent vs. infrequent contrast with stative predicates.

\subsection{BCVs in control structures}

For control sentences, participants were asked to rate four related sentences: one with no BCV (Spanish control verb with an English lexical verb), one with a BCV in the control verb (with an English lexical verb), a BCV in the main verb (with a Spanish control verb) or a double BCV (BCV in both control and main verbs). The descriptive statistics show that conditions with BCVs are within the acceptance rate while the condition without a BCV is not. The data also indicate that post-adolescent females rate BCVs lower than the other groups, while sentences without BCVs are rated lower by adolescent females.

In order to examine these comparisons, a 4 (sentence type: no BCV, BCV in the control verb, $\mathrm{BCV}$ in the main verb, and double BCV) by 4 (speaker group) repeated-measures ANOVA was performed, which revealed a main effect for sentence type, no main effect for speaker group and no sentence type by speaker group interaction (see Table 5). The Bonferroni post-hoc test revealed that sentences with a BCV in the main verb and sentences with a double BCV were rated 
Table 4. Descriptive statistics for control structures

\begin{tabular}{llrrr}
\hline $\begin{array}{l}\text { Descriptive statistics: } \\
\text { BCVs in control structures }\end{array}$ & Speaker group & Mean & $\begin{array}{l}\text { Std. } \\
\text { Deviation }\end{array}$ \\
\hline No BCVs & Adolescent females & 1.45 & 0.60 & 5 \\
& Adolescent males & 1.75 & 0.45 & 8 \\
& Post-adolescent females & 1.80 & 0.55 & 10 \\
& Post-adolescent males & 1.80 & 0.51 & 15 \\
& Total & 1.74 & 0.51 & 38 \\
BCV in the control verb & Adolescent females & 2.45 & 0.69 & 5 \\
& Adolescent males & 2.46 & 0.39 & 8 \\
& Post-adolescent females & 1.90 & 0.50 & 10 \\
& Post-adolescent males & 2.25 & 0.47 & 15 \\
BCV in the lexical verb & Total & 2.23 & 0.52 & 38 \\
& Adolescent females & 2.95 & 0.33 & 5 \\
& Adolescent males & 3.03 & 0.41 & 8 \\
& Post-adolescent females & 2.75 & 0.58 & 10 \\
& Post-adolescent males & 3.02 & 0.49 & 15 \\
& Total & 2.94 & 0.48 & 38 \\
& Adolescent females & 2.90 & 0.38 & 5 \\
& Adolescent males & 3.03 & 0.39 & 8 \\
& Post-adolescent females & 2.45 & 0.80 & 10 \\
& Post-adolescent males & 2.58 & 0.51 & 15 \\
& Total & 2.68 & 0.59 & 38 \\
\hline
\end{tabular}

significantly higher than sentences with a BCV in the control verb and these, in turn, were rated significantly higher than those without a BCV.

Table 5. ANOVA results for sentence type in control structures

\begin{tabular}{llll}
\hline $\begin{array}{l}\text { ANOVA results: } \\
\text { Sentence type }\end{array}$ & $\begin{array}{l}\text { Main effect for sentence } \\
\text { type }\end{array}$ & $\begin{array}{l}\text { Main effect for } \\
\text { speaker group }\end{array}$ & $\begin{array}{l}\text { Sentence type by speak- } \\
\text { er group interaction }\end{array}$ \\
\hline Control structures & $F(2.8,102)=49.400$, & $F(3,34)=1.530$, & $F(8.3,102)=1.402$, \\
& $p=.00$, & $p=.23$, & $p=.20$, \\
& partial $\eta 2=.592$ & partial $\eta 2=.119$ & partial $\eta 2=.110$ \\
\hline
\end{tabular}

To conclude this section, speakers rated BCVs significantly higher than sentences with a switch into an English verb. Predicate type, stativity, and frequency did not restrict the use of BCVs. Lastly, control structures are rated higher when the Spanish control verb is followed by a BCV or when the BCV is used in both the control and main verbs. 


\subsection{BCVs in oral production: stativity}

A total of 564 BCVs were extracted from the interviews, of which $98 \%$ were canonical 'hacer $+\mathrm{V}$ ' forms whereas non-canonical forms comprised the remaining $2 \%$. Among the non-canonical forms were BCVs in stative passives as in (3), in perfective forms (4), and in control structures (5), innovative constructions which have not been reported elsewhere in the Spanish/English literature on bilingual LV structures.

(3) En Sixth Form, tas hecho considered un adult In Sixth Form, be.2ndsg done considered.PASTPART an adult "In Sixth Form, you are considered an adult."

(4) Nuncahe hecho witness un girls' fight Never have.1stsg do.PASTPART witness.INF a girls' fight "I have never witnessed a girls' fight."

(5) Hay un program que hace allow hacer chat There is.3rdsg a program that does allow.INF do.INF chat.INF "There is a program that allows chatting."

Further analysis of the 553 canonical BCVs revealed that the LV construction occurred with 299 different lexical verbs. The total number of phrasal verbs in the corpus accounted for $10 \%$ of the lexical verbs, in contrast with $7.5 \%$ in Fotiou's (2012) Greek Cypriot/English corpus and less than 1\% in Wilson Vergara's (2013) New Mexican Spanish data. Even though their presence is higher than in other studies, phrasal verbs do not seem to comprise a significant portion of the type of lexical verbs that co-occur with the LV.

Consonant with the AJT data, stativity did not constrain the incorporation of stative verbs in BCVs (see Table 6). Stative verbs (e.g. hacer agree 'to agree', hacen keep 'they keep', hacemos need 'we need') accounted for less than 5\% of the English lexical verbs. Strikingly, however, BCVs with psychological verbs (e.g. hacerlo appreciate 'to appreciate it', hago feel 'I feel', hago realize 'I realize', haces understand 'you understand', hago trust 'I trust') accounted for a considerably higher percentage of lexical verbs. Noteworthy is that given the overlap in argument structure between these two types of verbs, if we considered stative and psychological verbs along with perception verbs as a single class, as it is done in the variationist literature (e.g. Aaron 2010), they would account for $20 \%$ of the total number of lexical verbs. 
Table 6. Lexical verb distribution in canonical BCVs

\begin{tabular}{lcr}
\hline Verb Type & Number of tokens & \multicolumn{1}{l}{$\%$} \\
\hline Activity & 156 & 28.2 \\
Change of state & 107 & 19.3 \\
Psychological & 82 & 14.8 \\
Communication & 55 & 9.9 \\
Other & 50 & 9.0 \\
Stative & 26 & 4.7 \\
Intransitive motion & 23 & 4.2 \\
Exchange & 22 & 4.0 \\
Reverse psychological & 16 & 2.9 \\
Transitive motion & 13 & 2.4 \\
Perception & 3 & 0.5 \\
TOTAL & 553 & 100.0 \\
\hline
\end{tabular}

The data showed that there was a tendency for BCVs to primarily occur with activity verbs. When combined as the class of dynamic verbs, activity verbs (e.g. hacerlo carve 'to carve it', hacen clean 'they clean'), intransitive motion verbs (e.g. haces gather 'you gather', hago lay down 'I lay down') and transitive motion verbs (e.g. hacer knock on sus heels 'to put on heels', hacer park sus car 'to park their car') account for $34.8 \%$ of lexical verbs. There was also a high rate of occurrence with change of state verbs (e.g. hizo decrease 'it decreased', hacer reinforce 'to reinforce', hacen shorten 'they shorten', se hizo burst 'it burst'), and 'other' lexical verbs, which were difficult to classify (e.g. portray, represent, allow, engage, etc.). Note, however, that if we combined change of state and 'other' verbs with reverse psychological predicates and the class of stative, psychological and perception verbs, which all lack clearly observable agentive action, this would account for more than $50 \%$ of lexical verbs.

Overall, the oral production data revealed that that there is no inherent feature in English lexical verbs that constrain their incorporation in BCVs. Though to varied degrees of frequency, BCVs were attested in transitive, intransitive, reflexive, passive and control structures. They were also attested with different types of verbs. Although BCVs particularly occurred with activity verbs, they were also attested with stative, psychological and change of state verbs.

\subsection{BCVs in oral production: frequency}

Also in line with the judgment data, the analysis of the oral production data further demonstrated that frequency does not constrain the incorporation of $\mathrm{BCVs}$ (see Figure 2). Although BCVs were attested primarily with low frequency verbs (i.e. $64.1 \%$ ), high frequency verbs accounted for $35.9 \%$ of the lexical verbs, which 
is considerably higher than the percentage reported by Fuller Medina (i.e. 4.5\%). A small percentage of low frequency verbs were highly infrequent (i.e. 9\%), with less than 100 occurrences. On the other hand, 15\% of the lexical verbs (not included in the scatter chart) were highly frequent, exceeding 10,000 occurrences in the Davies Corpus. Thus, BCVs occurred with both highly infrequent verbs (e.g. hace garnish 'to garnish', hacen discriminate people 'they discriminate people', hacerles revoke sus licence 'revoke their license', hacemos socialize 'we socialize') and highly frequent lexical verbs (e.g. estan haciendo have fun 'they are having fun', hago speak my mind 'I speak my mind', hacer live 'to live', puedes hacer wear 'you can wear').

In order to ensure comparability, frequency was operationalized following Fuller Medina. It must be pointed out, however, that future studies can possibly determine it as Erker \& Guy $(2012,530)$ did in their study on the effects of frequency on variable subject expression. Instead of operationalizing frequency based on online corpora, frequency was based on the corpus being analyzed so that it "approximates the usage prevailing in the local speech community." Such analyses could potentially reveal interesting results that could either support or refute our present findings. Thus far, a primary challenge for researchers who investigate bilingualism is that frequency counts based on online corpora reflect monolingual Spanish varieties rather than bilingual Spanish/English varieties (for further discussion on challenges on the quantification of frequency, see Erker and Guy 2012). In particular, the case of 'hacer $+V$ ' is more difficult to analyze, as it is not the prototypical case of morphosyntactic variation. BCVs, especially in the case of $\mathrm{NB}$, involve several varieties that evince phonological and grammatical overlaps; thus, determining whether the variant is present or not in the monolingual-like lexicon has to be examined on a case-by-case basis.

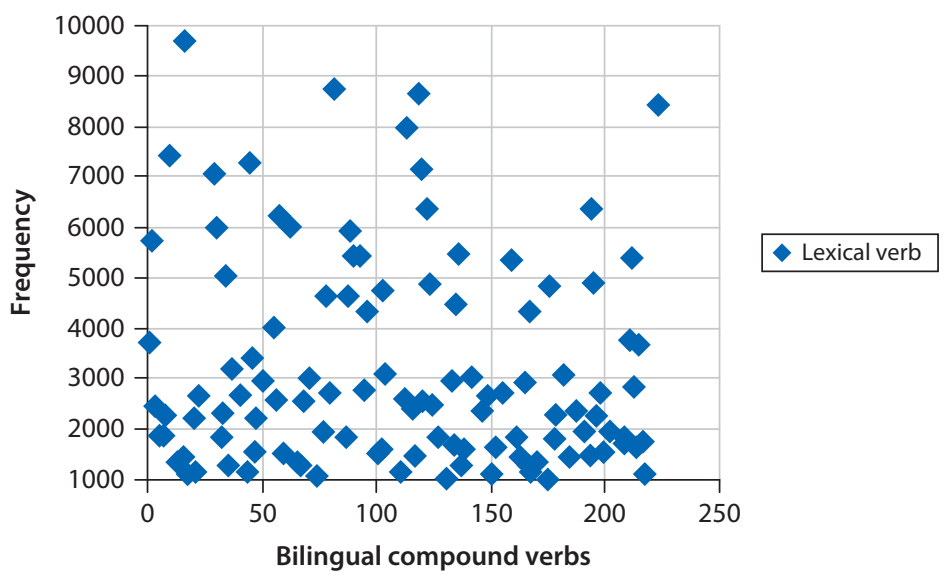

Figure 2. Frequency of lexical verbs in BCVs 


\section{Discussion}

The primary goal of the current study was to determine whether stativity and/or verb frequency constrain the incorporation of BCVs. Overall, results showed that both adolescent and post-adolescent speakers accepted BCVs across conditions. Noteworthy is that the non-canonical 'hacer $+\mathrm{V}+$ hacer $+\mathrm{V}$ ' was rated as acceptable but to a lesser degree in comparison to canonical constructions. It may be that this innovation is still in its early stages of diffusion or that it is only employed by more prolific code-switchers. In the oral production data, BCVs were found in a variety of verbal contexts, revealing that there is no inherent feature in verbs which constrain the incorporation of $\mathrm{BCV}$ s as previously contended in variationist work. In line with Wilson Vergara's (2013) suggestion, frequent code-mixing does seem to facilitate the conventionalization and grammaticalization of this construction. Thus, in the case of NB, where CS is pervasive and socially accepted (Balam 2013a), BCVs may have further grammaticalized. In light of the current study's findings, we would like to bring to the fore crucial aspects of the NB contact situation, which may help to explain the ubiquitous, creative use of BCVs; namely, speakers' attitudes to their language varieties, the availability of a BCV model and the possible effects of creolization on CS innovations.

Consonant with Gardner-Chloros $(1995,2010)$ and Sebba (1998), we contend that CS phenomena are largely dependent on the historical and social nature of bilingualism/multilingualism in a given context. As Sebba (1998,7-8) aptly underscores, "the locus of congruence is the mind of the speaker, but community norms determine, by and large, the behavior of individual speakers." Thus, although there are syntactic constraints, bilingual/multilingual speakers are able to not only "avoid the straitjacket of grammatical rules," (Gardner-Chloros and Edwards 2004, 108), but they can also build structural congruence in an effort to facilitate CS. Sebba explains that in the case of BCVs, code-switchers employ a neutralization strategy, where a "slot" for a congruent category is created as a means of avoiding non-congruent categories that would otherwise preclude a switch. In this case, the morpheme hacer ' $\mathrm{do} / \mathrm{make}$ ' is used as a way of resolving the switch incompatibility between the two languages. Thus, BCVs are a strategy code-switchers use to create a switch site and to maintain the rapid flow of effortless bilingual discourse. These switch sites seem to be malleable to change as they can accommodate intervening material such as fillers, quantifiers and adverbs (e.g. se hacen easily fall 'they easily fall', hago medio understand 'kind of understand', hacen mas try hace get along 'they try to get along more') and they can also be extended to other syntactic contexts.

An important social aspect of the NB contact situation is speakers' attitudes to CS and BK. Belizean Hispanic attitudes to BK were markedly negative in the colonial era (Koenig 1975, 1980). Efforts to revitalize the value of BK in 
post-Independent Belize, however, particularly from the Belize Kriol Council, has led to a significant shift in speakers' attitudes toward BK (Ravindranath 2009). In contrast to the U.S. context where CS is still largely ascribed a negative value (e.g. Anderson and Toribio 2007; Valdés, González, López García and Márquez 2003), bilingual and trilingual language alternation in Belize is largely perceived as positive and representative of speakers' 'mixed' identity. In a recent study on Hispanic Belizeans' attitudes to their language varieties, Balam (2013a) found that adolescent and post-adolescent speakers exhibited pejorative attitudes to standard Spanish rather than CS and BK. In particular, post-adolescent speakers were positively predisposed to bilingual/trilingual CS, whereas adolescents exhibited a more positive predisposition to BK. If speakers have more positive attitudes to non-standard varieties, then more than likely, they will have positive attitudes to the use of syntactic innovations. We know that in situations where there are "flexible identity boundaries" and lax parental and community attitudes to the use of non-standard innovative forms, there is a higher probability that innovative forms will spread across a multilingual community (Matras 2010, 72). Thus, speakers' positive language attitudes to non-standard varieties may have licensed the ubiquitous use of non-standard, innovative forms such as BCVs. However, research must be carried out to further understand speakers' attitudes, across age groups, in relation to BCVs.

Also relevant to the foregoing discussion is the availability of a native BCV model. Recall that many of the predecessors of today's trilingual speakers in Northern Belize were Spanish/Mayan bilinguals from Mexico. BCVs have been attested in Yucatan Spanish, the pre-contact variety of NBS (Suárez-Molina 1996). Examples of Yucatan Spanish/Mayan BCVs, still used in some rural areas in NB, are hacer chichis, 'lulling a baby to sleep,' hacer hich, 'tie a knot tightly', hacer lit'i, 'standing on toes', etc. It may be that in the advent of a rapid shift from Mayan/Spanish bilingualism to Spanish/English bilingualism during the 1940s and thereafter in NB (Koenig 1975, 82), speakers of the current bilingual/trilingual generation adopted the pre-existing native 'hacer $+\mathrm{V}$ ' model to devise even more innovative BCVs (e.g. 'hacer $+\mathrm{V}+$ hacer $+\mathrm{V}$ '). We know that bilingual/multilingual speakers build on the available syntactic resources they have. For instance, in Bengali/English CS, speakers use an available model in monolingual Bengali complex verb forms to create innovative three-part bilingual complex verbs (Chatterjee 2012). It has also been established that across generations, BCVs further grammaticalize (for the case of yap- in Turkish/Dutch, see Backus 1996).

Lastly, the existence of CS alongside an English-based Creole as a lingua franca cannot be undermined. CS has traditionally been examined in isolation of Creoles, even though both outcomes are in many ways reflective of similar social experiences. More recently, the focus has been on differentiating CS from Creoles 
or pidginization (Gardner-Chloros 2010). For example, Rodriguez-González and Parafita-Couto (2012) highlight different traits, such as the degree of morphological simplification, which differentiate CS from pidgins and creoles. However, although this analysis may be relevant to CS in the U.S., it is not easily applicable to situations where unlike the U.S., Spanish/English language alternation not only co-exists with a Creole, but enjoys relatively similar levels of prestige. The NB contact situation embodies such linguistic interplay, and consequently, the thin line between Spanish/English CS and BK must be more cautiously considered.

As a non-classic code-switching context where there is extensive CS alongside the pervasive use of BK, Belize certainly fits Gardner-Chloros' description of contexts where there is "linguistically intense and constraint-defying forms of code-switching" $(1995,79)$. The seemingly constraint-free kinds of innovation present in NB beg us to question whether there is in some way a correlation between language alternation and BK in Belize. The concurrent development of NBS as a commonly used bilingual variety alongside $\mathrm{BK}$ as a nascent prestige variety in the last three to four decades may have also contributed to the ubiquitous use of BCVs. Le Page and Tabouret Keller $(1985,11)$ remind us that particularly in cases of creolization, language becomes a game wherein speakers are not only the players who invent the rules of the game (Brown 1958) but also act as the umpires as well. There is the possibility that the widespread acceptance and use of Belizean Kriol may have further licensed the creative use of linguistic structures.

Gardner-Chloros $(2010,198)$ maintains that "[BCVs] show features of creolization, as they involve grammatical convergence and an analytic approach to vocabulary." This 'analytic approach' is certainly evident in speakers' skillful lexical and syntactic use of BCVs to succinctly express ideas (e.g. vamos a hace agree instead of vamos a ponernos de acuerdo 'We will agree to meet') and/or to add a markedly colloquial quality to their speech (e.g. Estaba haciendo run out de air 'He was running out of air'). Furthermore, Creole-like features are evident in NB code-switchers' use of BCVs. Although a phonetic analysis of hacer 'do/make' falls outside the purview of this paper, noteworthy is that in the oral production data, a distinctive pattern was the consistent pronunciation of the LV with a word-final null rhotic. As Figure 3 illustrates, the word final tap in hacer is deleted. Thus, in vernacular speech, the uninflected LV in bilingual infinitive constructions is actually pronounced as asé. Note that whereas s-deletion is characteristic of many Spanish varieties (Hualde et al. 2010), r-deletion in verbal infinitives, has been particularly attested in Spanish Creoles and Afro-Hispanic varieties (Hualde et al. 2010; Lipski 2007). In this regard, NBS shares certain phonetic features that are closer to Spanish creoles than to Central American and/or Caribbean Spanish varieties. 


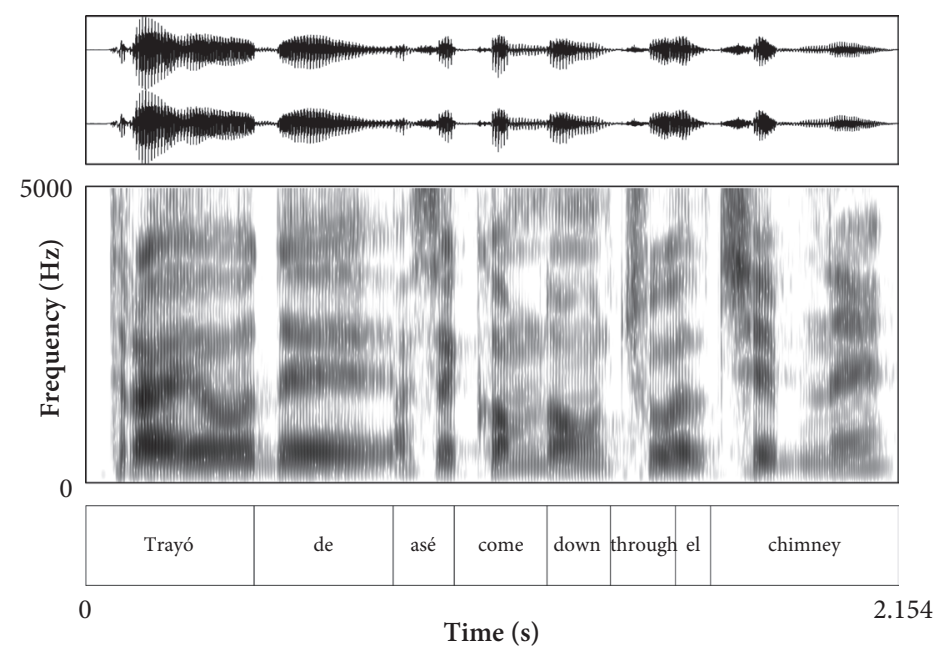

Figure 3. Creoloid asé 'do/make' in NB code-switching

Noteworthy is that the use of asé has been attested as a preverbal habitual and frequentative marker in Palenquero, a Spanish-lexified Creole spoken in Colombia (Smith 2013). Although researchers disagree on the etymology of asé in Palenquero, in the case of NB, it is rather uncontroversial that asé is derived from hacer 'do/make', especially since there are no other LV variants used in NB code-mixed speech, as it does in other CS varieties where different light verbs are used to encode semantic nuances such as stativity or voice (cf. Muysken 2000, 212)

There is no doubt bilingual/multilingual speakers maximize their linguistic resources and capitalize on grammatical parsimony (Matras 2010:83; Toribio 2004), and this may be more prominent in situations of linguistic convergence, as is the case of Belize (Hagerty 1996). The creative ability to build congruence can be instantiated and exploited, given the appropriate circumstances, in cases of nascent Creoles, emerging Creoloid phenomena and intensive language alternation. ${ }^{2}$ Although BCVs may seem superfluous and more morphologically complex, they are actually an example of 'adaptive simplification', in the sense of Otheguy and Lapidus (2003), where speakers no longer have to deal with phonologicallydriven exceptions to the Spanish inflectional system, but rather, their focus lies only on inflecting the LV. Thus, the Spanish verbal paradigm from this perspective is used more parsimoniously. BCVs are a strategic means of maximizing lexical resources in a bilingual/multilingual speakers' repertoire. In BCVs, the incorporation of phrasal verbs and verbs that lack equivalents are instantiations whereby, in

2. We adopt Platt's (1975) definition of a Creoloid, which refers to a variety with Creole features but which did not develop from a pidgin. 
Sebba's $(1998,8)$ terms, speakers establish "common ground" despite the semantic and syntactic incongruences that may exist in the verbal systems of the language varieties.

\section{Conclusion}

The current study showed that in NB, BCVs are not constrained by stativity or frequency. We have pointed out concomitant factors that may help to account for the ubiquitous use of BCVs in NB. Following the works of Le Page and TabouretKeller (1985), Sebba $(1998,2009)$ and Gardner-Chloros $(1995,2010)$, the current study postulates that Hispanic Belizean code-switchers' ubiquitous and creative use of BCVs can be accounted by speakers' positive language attitudes to CS and $\mathrm{BK}$, the availability of a pre-existing $\mathrm{BCV}$ model and their creative ability to exploit their rich linguistic NBS/English/BK repertoire. Although this study makes a novel contribution by examining data from an understudied contact situation, a limitation was the small sample examined. Also important in future investigation is the consideration of alternative ways to operationalize frequency. The current study opens an avenue for further research on interrelated social and linguistic phenomena related to BCVs in NB. For instance, a more thorough analysis of the clausal and sentential contexts in which BCVs occur could enlighten us as to how congruence is created at more syntactically complex levels. Most importantly, more in-depth, cross-regional investigation of social factors must be carried out (e.g. NB versus New Mexico), as this kind of comparative research will provide a more lucid, global understanding of how bilinguals/multilinguals manipulate their linguistic repertoire vis-à-vis the sociolinguistic atmosphere in which they are found.

\section{Acknowledgements}

This project was conducted thanks to the financial support of a Tinker Travel Grant, obtained via the Centre for Latin American Studies, University of Florida. We are very grateful to Mr. Javier Gutierrez and Mrs. Maria Johnston from Muffles College; and Mrs. Elizabeth Muschamp from Orange Walk Technical High School, who facilitated the data collection process in Orange Walk, Belize. We are also thankful to our participants. 


\section{References}

Aaron, Jessi E. 2010. "Pushing the Envelope: Looking Beyond the Variable Context." Language Variation and Change 22 (1): 1-36. DOI: 10.1017/S0954394509990226

Anderson, Tyler, and Almeida Jacqueline Toribio. 2007. "Attitudes Towards Lexical Borrowing And Intra- sentential Code-switching among Spanish-English Bilinguals." Spanish in Context 4 (2): 217-240. DOI: 10.1075/sic.4.2.05and

Balam, Osmer. 2013a. "Overt Language Attitudes and Linguistic Identities among Multilingual Speakers in Northern Belize." Studies in Hispanic and Lusophone Linguistics 6 (2): 247-277.

Balam, Osmer. 2013b. "Variable Neutralization of the Intervocalic Rhotic Contrast in Northern Belizean Spanish.” Borealis: An International Journal of Hispanic Linguistics 2 (2): 285-315. DOI: $10.7557 / 1.2 .2 .2601$

Backus, Ad. 1996. Two in One. Bilingual Speech of Turkish Immigrants in the Netherlands. Tilburg: Tilbury University Press.

Bolle, Jette. 2000. "Notas sobre los conflictos y contactos lingüíticos entre el maya yucateco, el español y el inglés en la zona de rio hondo." Estudios de Cultura Maya 21: 217-230.

Blom, Jan-Petter, and John J. Gumperz. 1972. "Social meaning in linguistic structure: codeswitching in Norway." In Directions in Sociolinguistics: The Ethnography of Communication, ed. by John J. Gumperz, and Dell Hymes, 407-434. New York: Holt, Rinehart \& Winston.

Brockmann, Thomas. 1979. "Language, Communication and Ethnicity in British Honduras." In Sociolinguistic Studies in Language Contact: Methods and Cases, ed. by William Francis Mackey, and Jacob Ornstein, 161-180. The Hague: Mouton Publishers.

Chatterjee, Tridha. 2012. “Bilingual Complex Verbs: So What's New about Them?” Paper Presented at the 38th Annual Meeting of the Berkeley Linguistics Society, Berkeley, CA.

Davies, Mark. 2002. Corpus del Español (100 Million Words, 1200's to 1900's). Retrieved from www.corpusdelespanol.org.

Edwards, Malcolm, and Penelope Gardner-Chloros. 2007. "Compound Verbs in Codeswitching: Bilinguals Making Do?” International Journal of Bilingualism 11 (1): 73-91. DOI: $10.1177 / 13670069070110010501$

Elías-Olivares, Lucía. 1976. Ways of Speaking in a Chicano Speech Community: A Sociolinguistic Approach. Doctoral dissertation, University of Texas, Austin.

Escure, Genevieve. 1982. "Contrastive Patterns of Intragroup and Intergroup Interaction in the Creole Continuum of Belize." Language in Society 11 (2): 239-264. DOI: 10.1017/ S0047404500009210

Erker, Daniel, and Gregory R. Guy. 2012. “The Role of Lexical Frequency in Syntactic Variability: Variable Subject Personal Pronoun Expression in Spanish.” Language 88 (3): 526-557. DOI: 10.1353/lan.2012.0050

Field, Fredric W. 2002. Linguistic Borrowing in Bilingual Contexts. Amsterdam: John Benjamins. DOI: $10.1075 /$ slcs.62

Fotiou, Constantina. 2012. "Are The Greek Verbs no Longer Enough? Bilingual Compound Verbs in Cypriot Greek." In Linguists of Tomorrow: Selected Papers from the 1st Cyprus Postgraduate Conference in Theoretical and Applied Linguistics, ed. by Kleanthes K. Grohmann, Aljona Shelkovaya, and Dionysios Zoumpalidis, 22-50. Newcastle-upon-Tyne: Cambridge Scholars Publishing. 
Fuller Medina, Nicté. 2005. "Spanish-English Contact in Belize: The Case of Hacer + V." In Proceedings of the 2005 Canadian Linguistics Association Annual Conference, ed. by Claire Gurski, 1-9. http://ling.uwo.ca/publications/CLA-ACL/CLA-ACL2005.htm.

Gardner-Chloros, Penelope. 1995. "Codeswitching in Community, Regional and National Repertoires: The Myth of the Discreteness of Linguistic Systems." In One Speaker Two Languages: Cross-disciplinary Perspectives on Codeswitching, ed. by Lesley Milroy, and Pieter Muysken, 68-89. Cambridge: Cambridge University Press. DOI: 10.1017/ CBO9780511620867.004

Gardner-Chloros, Penelope, and Malcolm Edwards. 2004. "Assumptions Behind Grammatical Approaches to Codeswitching: When the Blueprint is a Red Herring." Transactions of the Philological Society 102 (1): 103-129. DOI: 10.1111/j.0079-1636.2004.00131.x

Gardner-Chloros, Penelope. 2010. "Contact and Code-switching." In The Handbook of Language Contact, ed. by Raymond Hickey, 188-208. Malden, MA: Blackwell Riley. DOI: 10.1002/9781444318159.ch9

González-Vilbazo, Kay, and Luis López. 2011.” Some properties of light verbs in code-switching." Lingua 121 (5): 832-850. DOI: 10.1016/j.lingua.2010.11.011

González-Vilbazo, Kay, and Luis López. 2012. "Little v and Parametric Variation." Natural Language and Linguistic Theory 30 (1): 33-77. DOI: 10.1007/s11049-011-9141-5

Grosjean, Francois. 1998. "Studying Bilinguals: Methodological and Conceptual Issues." Bilingualism: Language and Cognition 1 (2): 131-149. DOI: 10.1017/S136672899800025X

Hagerty, Timothy W. 1979. Phonological Analysis of the Spanish of Belize. Unpublished Dissertation, University of California, Los Angeles.

Hagerty, Timothy W. 1996. "The Influence of English on the Spanish Language of Belize." In Belize: Selected Proceedings from the Second Interdisciplinary Conference, ed. by Michael D. Phillips, 131-142. Lanham, MD: University Press of America.

Hellinger, Marlis. 1973. "Aspects of Belizean Creole." Folia Linguistica 6 (1-2): 118-135. DOI: 10.1515/flin.1973.6.1-2.118

Hualde, Jose Ignacio, Antxon Olarrea, Anna Maria Escobar, and Catherine E. Travis. 2010. Introducción a la lingüística hispánica, 2nd ed. Cambridge: Cambridge University Press.

Jenkins, Devin L. 2003. "Bilingual Verb Constructions in Southwestern Spanish." Bilingual Review 27 (3): 195-204.

Koenig, E. L. 1975. Ethnicity and Language in Corozal District, Belize: An analysis of Codeswitching. Unpublished Ph.D. Dissertation, University of Texas at Austin, TX.

Koenig, E. L. 1980. "Ethnicity: the Key Variable in a Case Study of Language Maintenance and Language Shift." Ethnicity 7 (1): 1-14.

Le Page, Robert B. 1984. “The Notion of 'Linguistic System' Revisited.” International Journal of the Sociology of Language 109 (1): 109-120.

Le Page, Robert B., and Andrée Tabouret-Keller. 1985. Acts of Identity: Creole-based Approaches to Language and Ethnicity. New York: Cambridge University Press.

Lipski, John M. 2007. "Afro-Yungueno Speech: The long-lost 'Black Spanish.” Spanish in Context 4 (1): 1-43. DOI: 10.1075/sic.4.1.02lip

MacSwan, Jeff, and Kara T. McAlister. 2010. "Naturalistic and Elicited Data in Grammatical Studies of Codeswitching." Studies in Hispanic and Lusophone linguistics 3 (2): 521-532.

Matras, Yaron. 2010. “Contact, Convergence and Typology." In Handbook of Language Contact, ed. by Raymond Hickey, 66-85. Oxford: Blackwell. DOI: 10.1002/9781444318159.ch3

Migge, Bettina. 1995. “The Emergence of Creole Copulas: Evidence from Belize Creole.” Studies in Synchronic and Diachronic Variation. Working Papers in Linguistics 46: 63-85. 


\section{Osmer Balam, Ana de Prada Pérez and Dámaris Mayans}

Moberg, Mark. 1997. Myths of Ethnicity and Nation: Immigration, Work, and Identity in the Belize Banana Industry. Knoxville: University of Tennessee Press.

Muysken, Pieter. 2000. Bilingual Speech: A Typology of Code-Switching. Cambridge: Cambridge University Press.

Myers-Scotton, Carol. 1998. Codes and Consequences: Choosing Linguistic Varieties. New York: Oxford University Press.

Myers-Scotton, C. 2002. Contact Linguistics: Bilingual Encounters and Grammatical Outcomes. Oxford: Oxford University Press.

Otheguy, Ricardo, and Naomi Lapidus. 2003. "An Adaptive Approach to Noun Gender in New York contact Spanish.” In A Romance Perspective on Language Knowledge and Use, ed. by Rafael Núñez-Cedeño, Luis López, and Richard Cameron, 209-229. Amersterdam: John Benjamins. DOI: 10.1075/cilt.238.17oth

Platt, John. 1975. “The Singapore English Speech Continuum and its Basilect 'Singlish' as a 'Creoloid"' Anthropological Linguistics 17 (7): 363-374.

Ravindranath, Maya. 2009. Language Shift and the Speech Community: Sociolinguistic Change in a Garifuna Community in Belize. Doctoral dissertation, University of Pennsylvania.

Reyes, Rogelio. 1982. "Language Mixing in Chicano Spanish." In Spanish in the United States:Sociolinguistics Aspects, ed. by Jon Amastae and Lucía Elías-Olivares, 154-165. New York: Cambridge

Ritchie, William C., and Tej Bhatia. 1996. "Codeswitching, Grammar, and Sentence Production: The Problem of Dummy Verbs.” http://www.eric.ed.gov/ERICDocs/data/ericdocs2sq1/content_storage_01/0000019b/80/14/e1/ba.pdf.

Romaine, Suzanne. 1986. "The Syntax and Semantics of the Code-mixed Compound Verb in Panjabi/English Bilingual Discourse." In Language and Linguistics: The Interdependence of Theory, Data and Application. ed. by Deborah Tannen, and James E. Alatis, 35-50. Washington, DC: Georgetown University Press.

Rodriguez-González, Eva, and Carmen M. Parafita-Couto. 2012. "Calling for Interdisciplinary Approaches to the Study of Spanglish and its Linguistic Manifestations." Hispania 95 (3): 461-480.

Sankoff, David, Shana Poplack, and Swathi Vanniarajan. 1990. "The Case of the Nonce Loan in Tamil." Language Variation and Change 2 (1): 71-101. DOI: 10.1017/S0954394500000272

Sebba, Mark. 1998. "A Congruence Approach to the Syntax of Codeswitching." International Journal of Bilingualism 2 (1): 1-19.

Sebba, Mark. 2009. "On the Notions of Congruence and Convergence in Code-switching." In The Cambridge Handbook of Linguistic Code-Switching, ed. by Barbara E. Bullock, and Almeida Jacqueline Toribio, 40-57. Cambridge: Cambridge University Press. DOI: 10.1017/ CBO9780511576331.004

Smead, Robert. 1998. "English Loanwords in Chicano Spanish: Characterization and Rationale." The Bilingual Review 23 (2): 113-123.

Smith, Hiram. 2013. "Habitual Aspect Marking in Palenquero: Variation in Present Temporal Reference." In Selected Proceedings of the 6th Workshop on Spanish Sociolinguistics, ed. by Ana Carvahlo, and Sara Beaudrie, 97-108. Somerville, MA: Cascadilla Proceedings Project.

Suárez Molina, Victor. 1996. El español que se habla en Yucatán: Apuntamientos filológicos, 3rd ed. Mérida, Yucatán: Ediciones de la Universidad Autónoma de Yucatán.

Shoman, Assad. 2010. "Reflections on Ethnicity and Nation in Belize." In Documento de Trabajo. No. 9 / Document de Travail No. 9, México: Proyecto AFRODESC/EURESCL, 1-61. http:// www.ird.fr/afrodesc/IMG/pdf/Cuaderno9-SHOMANFINAL.pdf. 
Toribio, Jacqueline A. 2004. "Convergence as an Optimization Strategy of Bilingual Speech: Evidence from Code-switching." Bilingualism: Language and Cognition 7 (2): 165-173. DOI: $10.1017 /$ S1366728904001476

Toribio, Jacqueline A., Barbara Bullock, and Christian Greaser. 2012. "The Bilingual Compound Verb [hacer + VE] in Texas Spanish: The Value of Corpus Data." Paper Presented at the Hispanic Linguistics Symposium, Gainseville, FL.

Valdés, Guadalupe, Sonia V. González, Dania López García, and Patricio Márquez. 2003. "Language Ideology: The Case of Spanish in Departments of Foreign Languages." Anthropology \& Education Quarterly 34 (1): 3-26. DOI: 10.1525/aeq.2003.34.1.3

Wilson Vergara, Damian. 2013. "One Construction, Two Source Languages: Hacer with an English Infinitive in Bilingual Discourse." In Ana M. Carvalho, and Sara Beaudrie (eds.), Selected Proceedings of the 6th Workshop on Spanish Sociolinguistics, 123-134. Somerville, MA: Cascadilla Proceedings Project.

Wohlgemuth, Jan. 2009. A Typology of Verbal Borrowings. New York, Berlin: Mouton de Gruyter. DOI: $10.1515 / 9783110219340$

Young, Colville N. 1973. Belize Creole: A Study Of The Creolized English Spoken in the City of Belize, in its Cultural and Social Setting. Unpublished doctoral dissertation, University of York, England.

\section{Authors' addresses}

Department of Spanish and Portuguese Studies

170 Dauer Hall

Gainesville, FL 32611-7405 
